\title{
Risco e vulnerabilidade como analisadores nas políticas públicas sociais: uma análise crítica
}

\author{
Risk and vulnerability as criteria to evaluate social \\ and public policies: A critical analysis
}

Silvio José BENELLI

\section{Resumo}

É apresentada uma síntese crítica sobre o percurso histórico e o processo de institucionalização da Assistência Social como política pública; além disso toma-se o discurso sobre o risco social presente nela e também na política nacional para crianças e adolescentes como analisador das possibilidades normalizadoras da Psicologia e da Assistência Social. Para que a Assistência Social, incluindo-se os psicólogos, possa buscar um efetivo equacionamento do problema social, é preciso que se paute radicalmente - logo de início -, pelo enunciado ético que deve orientar seus efeitos: o sujeito cidadão de direitos.

Palavras-chave: Assistência Social; Avaliação institucional; Políticas públicas; Psicologia social.

\begin{abstract}
A critical overview of the historical journey and the process of institutionalization of social assistance as a public policy are presented. The discourse about the social risk involved in it and in the national policy for children and adolescents is also addressed for the analysis of the normalizing possibilities of Psychology and Social Care. In order for Social Assistance, including psychologists, to find effective solutions for social problems, it has to be - from the very beginning -, based entirely on the ethical statement, which should manage its effects on citizens as subjects of rights.
\end{abstract}

Keywords: Social assistance; Institutional evaluation; Public policies; Psychology, Social.

A Psicologia, na realidade brasileira contemporânea, vem buscando novos rumos e tem empreendido grandes esforços no sentido de adotar um compromisso ético com a transformação social (Bock, 2009), como pode ser verificado nos últimos congressos da categoria (Conselho Federal de Psicologia, 2010a, 2010b, 2011a, 2011b, 2013). Em- bora seja um conceito polêmico, essa proposta de transformação social inclui uma implicação ética com a busca da superação da encomenda social e estatal que se faz a todas as áreas das Ciências Humanas, inclusive à Psicologia, enquanto ciência e profissão: que produza ajustamento e adaptação social, normalidade e normativização do indivíduo

\footnotetext{
$\boldsymbol{\nabla} \nabla \nabla$
}

1 Universidade Estadual Paulista "Júlio de Mesquita Filho", Departamento de Psicologia Clínica, Programa de Pós-Graduação em Psicologia. Av. Dom Antonio, 2100, Parque Universitário, 19806-900, Assis, SP, Brasil. E-mail: <benelli@assis.unesp.br>. 
(Figueiredo, 2007; Foucault, 1999). Inclui, portanto, um claro alinhamento com os interesses dos pobres, oprimidos, explorados e excluídos da sociedade capitalista.

A ação do psicólogo, em última instância, se dá em contextos que se encontram estabelecidos no cenário de instituições da sociedade, de acordo com Benelli (2004, 2009, 2010) e Constantino (2010), sendo esse seu intermediário necessário, sobretudo no âmbito das políticas públicas. Desse modo, esse profissional normalmente realiza diferentes formas de atuação, promovendo intervenções e também intercessões em dispositivos institucionais complexos. A própria ação do psicólogo também estabelece relação ativa e complexa com esse cenário institucional, no qual costuma desenvolver suas atividades profissionais (Alberto, 2012; Vasconcelos, 2008).

É sobre esse âmbito da prática profissional e de seus modos de constituição sobre o fazer do psicólogo que esses congressos buscam orientar e definir os modos de intervenção teórico-técnica desse profissional nos variados sistemas institucionais, como o prisional, o educacional e o laboral, no sentido de auxiliar o psicólogo na configuração de uma prática que seja crítica e transformadora (Conselho Federal de Psicologia, 2010b, 2013; Vasconcelos, 2008). Contudo, é preciso admitir que, dada a ampla diversidade da área da Psicologia, nem todos os profissionais estão sintonizados com essa proposta ou buscam efetivamente desenvolver uma prática mais crítica, como observam Macedo e Dimenstein (2009).

Nesse contexto de politização dos saberes teórico-técnicos da Psicologia, de engajamento social e de luta pela transformação social, abrem-se novos campos de intervenção para o profissional psicólogo, como, por exemplo, uma atuação avisada e politicamente informada e situada no vasto campo das políticas públicas (Rodrigues, 2010) e, particularmente, no âmbito da Assistência Social, conforme se pode verificar em Benelli e Costa-Rosa (2012a), Conselho Federal de Psicologia (2007), Cruz e Guareschi (2009, 2012), Paiva e Yamamoto (2010), Yamamoto (2007), Yamamoto e Oliveira (2010). Já não se trata apenas de propor novas técnicas ou de construir novas referências para a ação, mas de enfatizar uma participação propriamente política (Benelli, 2012b, 2013; Senra \& Guzzo, 2012).

Considerando um conjunto de possibilidades e limites para a Psicologia na sociedade capitalista explicitado por Yamamoto (2007), é possível inferir que ela, enquanto área de saber e modos de fazer, já detém condições de instrumentalizar a realização de intervenções e intercessões nas quais pode elaborar novos conhecimentos, incursionar por áreas adjacentes dos saberes disciplinares e, ao mesmo tempo, empreender ações propriamente políticas que têm incidência nos rumos da realidade social. O campo da Assistência Social como política pública e também o dos direitos da criança e do adolescente estão se abrindo como importantes frentes de trabalho, intervenção, pesquisa e intercessão para os profissionais da Psicologia, tanto em uma clínica psicoterápica, segundo Araújo (2010), Cruz (2009), Oliveira, Dantas, Solon e Amorim (2011), Yamamoto e Oliveira (2010), apesar dos parâmetros indicados pelo Conselho Federal de Psicologia (2007), quanto em uma perspectiva psicossocial, como propõem Benelli e Costa-Rosa (2013), Cruz e Guareschi (2009, 2012), Silveira, Cobalchini, Menz, Valle e Barbarini (2007). A divulgação de informações, o debate e processos de formação nessa temática são importantes tanto para alunos de Psicologia quanto para profissionais que atuam na rede socioassistencial, visando contribuir para uma inserção crítica e transformadora nesse âmbito.

Atualmente, os psicólogos estão cada vez mais envolvidos com trabalhos em entidades assistenciais e em diversos estabelecimentos institucionais os quais implementam políticas públicas em múltiplos setores: infância, adolescência, famílias, idosos, pessoas com deficiências, comunidades, saúde etc., tanto no âmbito federal quanto no estadual e no municipal (Benelli, 2012b; Cruz \& Guareschi, 2009, 2012). É fundamental que esses profissionais tenham conhecimento da problemática mais ampla que envolve a Assistência Social e seus temas conexos no Brasil, como apontado, por exemplo, por Benelli e Costa-Rosa (2010, 2011, 2012a, 2012b).

Este artigo pretende oferecer uma contribuição crítica aos psicólogos que trabalham nesse 
campo em particular, discutindo as aporias entre as questões do risco e da vulnerabilidade no contexto da Assistência Social como política pública. Este trabalho é resultante de uma longa inserção militante na área das políticas públicas de Assistência Social e naquelas direcionadas às crianças e adolescentes, por meio da qual desenvolve-se um conjunto de atividades profissionais nesses contextos institucionais na Região Centro-Oeste do interior do Estado de São Paulo: pesquisas acadêmicas, trabalhos de assessoria, realização de cursos e supervisão de estágio nessa área para alunos de um curso de Psicologia de uma universidade pública.

Além dessas atividades acadêmicas relativas ao campo assistencial, têm sido ainda desenvolvidos trabalhos de supervisão institucional em um Centro Especializado de Assistência Social (CREAS) da região, bem como palestras e cursos de formação para trabalhadores de entidades assistenciais e também para conselheiros municipais. Todos esses trabalhos proporcionaram um rico e complexo conjunto de observações, informações, conhecimentos e aprendizado, permitindo apresentar tanto uma série de problematizações históricas e conjunturais quanto algumas análises paradigmáticas sobre as relações entre a Psicologia e a Assistência Social. As discussões apresentadas emergem a partir desse pano de fundo da experiência concreta no campo social.

Neste artigo, adotou-se uma perspectiva institucional dialética para a organização do pensamento científico, por meio do qual o intelectual, já tendo chegado a uma elaboração do pensamento consistente e resolvida sobre certo tema, produz uma escrita lógica, concatenada e singular. Entende-se que é importante a existência de coordenadas claras em uma área ainda pouco estudada e nebulosa para que a intervenção profissional do psicólogo seja efetivamente capaz de promover a busca do equacionamento dos problemas sociais - no sentido de tornar lógica e intelectualmente compreensível, de sistematizar e avaliar a complexidade exigente dos seus diversos elementos constitutivos essenciais -, de modo crítico, dialético, ético e potencialmente transformador, superando a psicologização normalizadora típica da Psicologia e evitando também propostas pragmáticas e meramente paliativas (Senra \& Guzzo, 2012).

\section{Breve percurso histórico sobre o processo de institucionalização da Assistência Social no Brasil}

Apenas recentemente o Brasil passou a rumar para uma modernização da assistência a crianças pobres e suas famílias. O maior indicativo disso poderia ser verificado no atual processo de institucionalização estatal da política de Assistência Social e na implementação de seus estabelecimentos institucionais, programas, projetos, serviços e benefícios, nos quais os psicólogos estão incluídos.

Em seu longo processo de institucionalização, as práticas sociais de assistência configuram um conjunto de possibilidades variadas e distintas, inclusive concorrentes e alternativas entre si, como se pode verificar em Abreu e Castro (1987) e em Benelli e Costa-Rosa (2012a). É pertinente caracterizar sinteticamente alguns aspectos históricos desse amplo movimento institucional. Privilegia-se uma abordagem institucional analítica (Benelli \& Costa-Rosa, 2011), descritiva e crítica para embasar essa apresentação e discussão do tema.

Os diversos grupos religiosos, já de longa data, vêm desenvolvendo práticas sociais de assistência a partir da noção central de caridade (Benelli \& Costa-Rosa, 2012a; Souza, 2012). O discurso que aí se articula enuncia um conjunto de significantes específicos para denominar seu objeto: os pobres são denominados pedintes, carentes e assistidos e os meios de trabalho se baseiam na ajuda ao próximo, no auxílio aos pobres, no fazer o bem ao próximo por amor a Deus. Historicamente, as práticas piedosas de proteção aos desvalidos, aos viciosos e aos culpados por furtos buscavam, sobretudo, a salvação de suas almas. Quando esses grupos, constituídos por diferentes denominações religiosas - católicos, evangélicos, espíritas etc. -, passaram a incorporar o tema dos direitos humanos como uma certa expressão contemporânea de suas ações caritativas centradas no fazer o bem, também puderam designar seu trabalho como sendo uma ação de promoção humana, baseada na solidariedade para com os mais pobres e menores abandonados.

A elite dominante, ao ser constituída por burgueses que enriqueceram com a criação da indústria 
e com o trabalho fabril embasados em propostas humanistas e científicas secularizadas, deu origem a práticas sociais de assistência próprias, do que se pode designar como sendo a filantropia benemerente, como afirmam Benelli e Costa-Rosa (2012a) e Donzelot (2001). Os empresários industriais, preocupados com as difíceis condições de vida da classe trabalhadora e dos inúmeros pobres os quais povoavam a periferia das cidades, tomaram a iniciativa de oferecer auxílio a esses indivíduos considerados desvalidos da sorte. Os homens de bem, proprietários, pais de família, membros respeitáveis da boa sociedade procuraram, por meio do aconselhamento, a moralização virtuosa da conduta individual e da educação para o trabalho por meio do próprio trabalho, transformando os pobres em trabalhadores operosos e em homens úteis para a sociedade. Com isso, se pretendia evitar que os pobres mergulhassem na vagabundagem, na ociosidade e, daí, passassem para a marginalidade e criminalidade (Coimbra \& Nascimento, 2005).

A filantropia oferece uma proteção a qual visa, preventivamente, assistir, reformar, corrigir e regenerar os pobres, os menores delinquentes e vagabundos vistos como potencialmente perigosos, evitando que se tornem futuros criminosos. A assistência se caracterizava pelo trabalho voluntário, não profissionalizado, amador e improvisado. Além disso, a esfera da moralidade pessoal consiste um plano privado individual e não é adequada para fundamentar direitos sociais (Benelli \& Costa-Rosa, 2012a).

Incluídos em processos históricos complexos que envolvem diversos atores sociais, observa-se que os ocupantes dos cargos de governo também costumam realizar práticas sociais assistenciais, pois não podem deixar de fazer algo em favor de uma ampla parcela da população que vive na pobreza - mesmo que apenas com valor simbólico (Benelli \& Costa-Rosa, 2012a). As primeiras-damas passaram a gerir uma instância de trabalho social a qual poderia ser denominada de Fundo Social Municipal de Solidariedade, cuja função consistia em promover ações assistencialistas focalizadas por meio de campanhas de arrecadação variadas para posterior doação, por exemplo, de roupas e cobertores no inverno, ali- mentos e brinquedos na época do Natal etc. Ainda hoje, essa ajuda costuma ser coletada junto à sociedade civil e doada aos pobres pela autoridade municipal, gerando uma boa imagem para o governante e demonstrando sua atenção e preocupação com os mais pobres (Demo, 1995).

No campo concreto da realidade social, nota-se que os ocupantes de cargos da administração municipal tendem a ser paternalistas com os pobres, tratando-os de modo personalizado por meio de ajudas e favores individuais, configurando relações de compadrio, de familiarização das relações sociais, de concessão e benesse (Benelli \& Costa-Rosa, 2012a) ao arrepio da lógica da cidadania. As autoridades públicas encontraram, na medicina higienista e eugênica do século XIX, como explica Zaniani (2008), importante suporte em termos de fundamentação científica para lidar com a infância pobre, denominada, então, de "problema do menor" (Hillesheim \& Cruz, 2009, p.73). Aí também se verifica o atravessamento com o Direito, a Polícia e o Judiciário, por causa das questões relacionadas com a responsabilidade penal.

Tomemos o exemplo da filantropia no início do século XIX: pessoas que vêm se ocupar da vida dos outros, de sua saúde, da alimentação, da moradia... . Mais tarde, dessa função confusa, saíram personagens, instituições, saberes... uma higiene pública, inspetores, assistentes sociais, psicólogos (Foucault, 1979, p.151).

Emerge, no Brasil, ainda no final do século XIX, percorrendo todo o século XX e persistindo até os dias atuais, a plausibilidade social de internar as crianças e adolescentes pobres em instituições totais e disciplinares, como cartografadas por Goffman (1987) e Foucault (1999). É possível considerar que, inclusive após a promulgação do Estatuto da Criança e do Adolescente (ECA) (Brasil, 1990), os estabelecimentos de internação ainda não conseguiram superar a lógica disciplinar (Saliba, 2006; Silva, 2002).

A infância pobre, tida como abandonada, desvalida, em situação irregular, órfã, que vivia nas ruas, foi classificada como potencialmente perigosa para a sociedade. Sua pobreza foi interpretada, pela 
Psiquiatria e pela Psicologia psicométrica, como sendo da ordem do "desajuste psíquico", do "desvio de caráter", da "personalidade antissocial e psicopática" (Patto, 1997, 2010). Isso representava uma justificativa científica para os procedimentos de internação, com vistas a proteger, tratar e reeducar esses indivíduos. Da pobreza, enquanto fenômeno de ordem política, social e econômica, que inclusive pode ser entendida a partir de perspectivas unidimensionais e multidimensionais, como afirmam Accorsi, Scarparo e Guareschi (2012), há um deslizamento para o plano psíquico, para a personalidade como espaço psicológico interno do indivíduo. Passa-se da Política para a Psiquiatria e para a Psicologia, revelando um processo intenso de medicalização e de psicologização do social (Donzelot, 2001).

A família, o local de moradia e o trabalho, tomados enquanto modelos ideais de normalidade, passaram a ser a régua com que se mensurava os indivíduos tidos como estando em situação irregular. No estabelecimento de internação, a partir de uma determinação judicial sancionadora a qual privava crianças e adolescentes da liberdade, técnicas psicológicas e pedagógicas, repressivas e ressocializadoras deveriam ser empregadas para tornar a punição efetivamente terapêutica e educativa.

Não há como negar que essa descrição de um conjunto de práticas assistenciais problemáticas continua presente e operante na atualidade, como se pode verificar em Accorssi et al. (2012), em Benelli (2012a), em Benelli e Costa-Rosa (2011, 2012a), em Oliveira e Amorim (2012) e em Senra e Guzzo (2012). Contudo, o Brasil, na década de 1980, enquanto organização política estatal, diante das muitas pressões internas oriundas dos movimentos populares descontentes com condições de vida insuportáveis, somada à ação reivindicadora de inúmeros outros segmentos sociais e premido também por pressões internacionais, viu-se obrigado a enfrentar o "problema social" que se avolumava ao longo da sua história de formação. Adultos, crianças e adolescentes pobres se tornaram questões de política pública e passaram a ser considerados sujeitos de direitos e cidadãos (Brasil, 1988, 1990, 1993).

\section{O Sistema Único de Assistência Social e a política nacional para a criança e $o$ adolescente e os analisadores risco social e situação de vulnerabilidade}

O Sistema Único de Assistência Social representa, sem dúvida, uma considerável transformação no plano institucional e político da Assistência Social, elevando-a à categoria de instituição social (Benelli \& Costa-Rosa, 2013). Esta inclui saberes e práticas, dispositivos e equipamentos, discursos, poderes e atores sociais diversos que a operacionalizam, bem como objetos específicos os quais recorta no campo social, como se encontra estabelecida na realidade brasileira (Brasil, 2004, 2005, 2006a, 2009b, 2011, 2012a). Organizado nos níveis de Proteção Social Básica e Especial, o Sistema Único de Assistência Social instituiu o Centro de Referência da Assistência Social (CRAS) (Brasil, 2006b, 2006c, 2009a) e o CREAS (Brasil, 2006d), implementou um amplo conjunto de serviços socioassistenciais (Brasil, 2009b) e também incluiu em sua lógica as numerosas entidades filantrópicas anteriormente existentes. Entretanto, é possível questionar até que ponto ele seria paradigmaticamente contraditório, em sentido dialético, com relação aos modos históricos de lidar com a questão social - entendida como conjunto dos efeitos constitutivos da contradição capital-trabalho, expressos na produção massiva da desigualdade social, como postulada pela perspectiva marxista.

Em termos conceituais, pode-se observar uma transição discursiva dos temas da delinquência e da marginalidade, próprios de uma sociedade disciplinar normalizadora das condutas individuais (Foucault, 1999), para o do risco social e da vulnerabilidade, mais característicos de uma sociedade de controle, como caracterizada por Deleuze (1992) e Hardt e Negri (2001), pautada na gestão e administração da população, como propõem Castel (1987) e Andrade e Romagnolis (2010). O conceito analisador institucional é uma ferramenta importante para essa reflexão. Um analisador, de acordo com Lourau (1995, p.282) e Baremblitt (1998, p.69), não precisa ser constituído de material verbal; pode ser um monumento, uma planta arquitetônica, um arquivo, uma distribuição do tempo ou espaço na 
organização. Sua materialidade expressiva é totalmente heterogênea. Ele sempre é analítico em si mesmo, contendo elementos para se auto entender, para começar o processo de seu próprio esclarecimento. É um produto que pode analisar-se. Os analisadores podem ser históricos quando são produzidos na história e no próprio contexto da instituição analisada, mas também podem ser construídos, inventados com o objetivo de explicitar os conflitos e resolvê-los.

Pretende-se, dessa maneira, discutir as noções de risco social e de situação de vulnerabilidade como analisadores institucionais nas políticas públicas de Assistência Social e também para crianças e adolescentes, expressando processos de psicologização da realidade social. Através desses processos são produzidas explicações e eventuais soluções para os problemas sociais em uma perspectiva de abordagem predominantemente unidirecional, clínica, individualizada e especializada, não considerando o complexo processo de produção social e política dos fenômenos, como descritos por Benelli (2009), Castel (1987) e Foucault (1999).

Se durante os séculos XIX e XX predominou, no Brasil, a série dos significantes pobre-delinquente-perigoso-anormal-menor-abandonado-infrator, nas duas últimas décadas do século XX emergiu uma nova série no discurso oficial, como se pode verificar por meio da literatura e de uma presença atenta no campo: pobre-criança-adolescente-cidadãos-sujeitos-de-direitos-proteção-integral. Os deslizamentos semânticos vão compondo possibilidades paradigmáticas disciplinares alternativas. Embora se tenha enunciado a cidadania para os pobres tanto na Assistência Social - enquanto política pública de Estado -, quanto na Política Nacional dos Direitos Humanos de Crianças e Adolescentes e no Plano Decenal dos Direitos Humanos de Crianças e Adolescentes (Brasil, 2010a, 2010b, 2010c), o discurso oficial tergiversa e emprega os novos significantes do risco social e da vulnerabilidade. Estes remetem à sociedade de controle (Deleuze, 1992), reeditando, de modo repaginado, os antigos temas criados na sociedade disciplinar (Foucault, 1999), os quais já foram utilizados para mistificar a questão social: a delinquência perigosa, que precisa ser reprimida e controlada preventivamente, a anormalidade psíquica, afetiva, cognitiva e moral, as quais precisam ser corrigidas e tratadas, sendo que o indivíduo passa a ser normalizado e normativizado (Cruz \& Guareschi, 2004, 2009, 2012; Hillesheim \& Cruz, 2009). Parece mais do mesmo, sob novas roupagens, enquanto se evita lidar com a pobreza no plano social e no campo próprio da política pública.

Na contramão da mistificação psicologizante do social, entende-se, a partir de Costa-Rosa (2000, p.157), que o que não pertence à "faixa do tratável" deve ser equacionado no âmbito adequado. O pobre, criança ou não, é membro de uma classe social explorada, expropriada, marginalizada, excluída. Isso é um fato de ordem eminentemente política. Não é incomum que a polícia, os que exercem os poderes legislativo, judiciário, executivo e inclusive os trabalhadores da Assistência Social os considerem "marginais", "delinquentes", "perigosos", uma ameaça contra a qual é preciso defender a sociedade. No caso desses atores sociais, pode-se pensar que práticas de prevenção, repressão, contenção, aprisionamento, correção e vigilância sejam boas estratégias.

Quando se analisam alguns significantes presentes no discurso oficial da Assistência Social, como "situação pessoal e social de risco" ou de "vulnerabilidade" (Brasil, 2004, 2005, 2012b), verifica-se que se tratam de eufemismos mais ou menos recentes do ideário politicamente correto, o qual pretende substituir certos termos tidos como desagradáveis. Isso porque, de acordo com os textos oficiais, já não parece de bom tom denominar os indivíduos que precisam da Assistência Social como pobres, pois o termo conota dimensões políticas, sociais e econômicas demasiado fortes e algo incômodas para a gestão do social que implementa procedimentos técnicos assepsiados para lidar com o problema social e suas múltiplas refrações na sociedade.

É interessante observar que a Constituição Federal (Brasil, 1988) e o Estatuto da Criança e do Adolescente (Brasil, 1990), por exemplo, reconhecem e afirmam que esses indivíduos são cidadãos 
portadores de direitos e de deveres, pretendendo superar a lógica do antigo Código de Menores (Brasil, 1927, 1979). Essa lógica menorista pode ser entendida como um conjunto de saberes e fazeres determinado por uma teoria filantrópica a qual distingue crianças e adolescentes de menores delinquentes. Essa perspectiva se plasmou no Código de Menores (Brasil, 1927, 1979) e criou a doutrina da situação irregular, criminalizando a pobreza. O aparato político-jurídico institucionalizou uma série de equipamentos sociais com finalidades repressivas, punitivas e correcionais para enquadrar os menores.

Apesar da promulgação do Estatuto da Criança e do Adolescente no ano de 1990, ainda se nota uma persistência da lógica menorista nos discursos e práticas institucionais de atendimento a esse público, em uma espécie de retorno do recalcado. Aparentemente, como essa condição cidadã não pode ser garantida por uma ordem social capitalista, então, na elaboração dessa contradição, o discurso oficial produziu uma curiosa modificação discursiva que converteu crianças e adolescentes cidadãos de direitos e de deveres em pessoas ou indivíduos em situação de vulnerabilidade social ou de risco social. O sujeito cidadão foi convertido e transmutado, assim, em indivíduo vulnerável ou em risco (Coimbra \& Nascimento, 2005).

Tanto os textos oficiais das políticas públicas para crianças e adolescentes (Brasil, 2010a, 2010b, 2010c, 2012b) quanto os da Assistência Social (Brasil, 2004, 2005, 2011, 2012a) adotam e difundem a noção problemática de que "crianças e adolescentes estão em situação pessoal e social de risco", ou que os indivíduos estão em "situação de vulnerabilidade social". E, lamentavelmente, diversos profissionais da Psicologia parecem estar assumindo, sem maiores questionamentos, essa terminologia, o que pode ser verificado, por exemplo, em Alberto et al. (2008), em Barreto (2011), em Lima e Cerveny (2012) e ainda em Siqueira e Dell'Aglio (2011), em um novo processo de naturalização pseudossociologizante da desigualdade social. Talvez essa seja uma forma contemporânea de se traduzir a antiga questão da "situação irregular" (Brasil, 1979).
A pergunta impertinente é a seguinte: quem cria essas situações pessoais e sociais de risco ou as situações de vulnerabilidade social? Certamente, elas são efeito do modo de funcionamento do sistema capitalista e da sua lógica de acumulação. Nesse sentido, pode-se considerar que são também muitos os chefes do poder executivo, vereadores, secretários municipais, ricos empresários, entre inúmeros outros que, por meio de ações, omissões, negligência, descaso, violência, corrupção e ganância, lesam os direitos de cidadania dos munícipes, maiormente dos pobres e, dentre eles, das crianças e adolescentes?

Observa-se que a noção de risco tem feito fortuna no mundo acadêmico, gerando uma série de efeitos sociais. Se o indivíduo delinquente foi uma figura social produzida e recortada pela sociedade disciplinar, o "indivíduo em risco", como caracterizado por Bello (2007), Castel (1987), Costa (2004), Foucault (2008), Hardt e Negri (2001), Mendola (2005), Morais e Nascimento (2002), Pogrebinschi (2004), Oliveira e Heckert (2013), Traversini e Bello (2009), Vaz (1999), autores os quais operam de modos diversos com a categoria fundamental de "risco social", seria seu equivalente na atualidade, representando uma das estratégias do novo arranjo societário, baseado no conceito de controle, enquanto um monitoramento permanente que visa calcular, prever e tornar sem efeito possíveis ameaças sociais.

\section{Conclusão}

No plano da assistência aos pobres de todas as idades, as práticas realizadas e os discursos enunciados por diversos conjuntos de atores sociais ao longo da história, incluindo grupos de diferentes denominações religiosas, de industriais e de empresários, de autoridades políticas, de juristas, de médicos, de psiquiatras, de pedagogos, assistentes sociais, educadores e psicólogos, podem ser nomeados com muitos significantes: ajuda, auxílio, proteção, fazer o bem, assistir, promover, reprimir, prevenir, corrigir, reformar, regenerar, reeducar, aconselhar, ressocializar, formar pessoas de bem. É importante enunciá-los todos, de modo sistemático, 
pois radicalizar a análise permite dar mais visibilidade ao que se pretende superar, incluindo tanto a crítica quanto a denúncia, sem concessões suavizadoras.

As transformações históricas evidenciam a formação de um sistema assistencial com características predominantemente preventivas, correcionais, repressivas e ressocializadoras, com atravessamentos institucionais entre a Assistência Privada, de caráter religioso e filantrópico tradicional, a Assistência Pública, a Justiça, o Judiciário e um conjunto de Ciências Humanas disciplinares: Psiquiatria, Psicologia, Pedagogia e Serviço Social. No entanto, a Assistência Social, como política pública de Estado, explorando as brechas e as contradições da sociedade capitalista e baseando-se nos interesses do polo subordinado, deve pautar-se pela lógica dos direitos: humanos, civis, políticos, sociais; deve pautar-se pela ética da cidadania integral, não pela bondade pessoal, pela sensibilidade benemerente, pela proteção repressiva e moralista, pela moral pessoal ou pela cultura do favor clientelista e promotor de subalternidade.

O desafio consiste em construir práticas de atenção psicossocial que possam superar tanto as práticas disciplinares quanto as de controle na atualidade. Para que a Assistência Social, incluindo-se os psicólogos, possa buscar um efetivo equacionamento do problema social, é preciso que se paute radicalmente - logo de início -, pelo enunciado ético que deve orientar seus efeitos: o sujeito cidadão de direitos.

\section{Referências}

Abreu, S. F. A., \& Castro, M. M. P. (1987). A arte de administrar a pobreza: a assistência social institucionalizada em São Paulo. In I. A. Tronca (Org.), Foucault vivo (pp.101-110). Campinas: Papirus.

Accorssi, A., Scarparo, H., \& Guareschi, P. (2012). A naturalização da pobreza: reflexões sobre a formação do pensamento social. Psicologia e Sociedade, 24(3), 536-546.

Alberto, M. F. P. (2012). Pensamento crítico, formação de psicólogo e atuação junto à infância e juventude. Estudos de Psicologia (Natal), 17(3), 421-426.

Alberto, M. F. P., Almeida, D. R., Dória, L. C., Guedes, P. C., Sousa, T. R., \& França, W. L. P. (2008). O papel do

742 centes em situação de risco. Psicologia: Ciência e Profissão, 28(3), 558-573.

Andrade, L. F., \& Romagnolis, R. C. (2010). O Psicólogo no CRAS: uma cartografia dos territórios subjetivos. Psicologia: Ciência e Profissão, 30(3), 604-619.

Araújo, F. I. C. (2010). "Mas a gente não sabe que roupa a gente deve usar..." . Um estudo sobre a prática do psicólogo no Centro de Referência da Assistência (CRAS) (Dissertação de mestrado não-publicada). Pontifícia Universidade Católica de São Paulo.

Baremblitt, G. F. (1998). Compêndio de análise institucional e outras correntes: teoria e prática. Rio de Janeiro: Record.

Barreto, A. F. (2011). Sobre a dor e a delícia da atuação do psicólogo no SUAS. Psicologia: Ciência e Profissão, 31(2), 406-419.

Bello, E. (2007). 'Bio-poder' e 'sociedade de controle': duas contribuições de Michel Foucault para a análise social e política dos direitos humanos. Recuperado em agosto, 10, 2011, de http://www.mundojuridico. adv.br

Benelli, S. J. (2004). A instituição total como agência de produção de subjetividade na sociedade disciplinar. Estudos de Psicologia (Campinas), 21(3), 237-252. http://dx.doi.org/10.1590/50103-166×20040003 00008

Benelli, S. J. (2009). A cultura psicológica no mercado de bens de saúde mental contemporâneo. Estudos de Psicologia (Campinas), 26(4), 515-536. http://dx.doi. org/10.1590/50103-166×2009000400012

Benelli, S. J. (2010). Cartografia das instituições de assistência social a crianças e adolescentes num município do interior do Estado de São Paulo (Tese de pós-doutorado não-publicada). Universidade Estadual Paulista, Assis.

Benelli, S. J. (2012a). Pistas pedagógicas para a socioeducação de crianças e adolescentes na entidade assistencial. In O. C. Mattioli, M. F. Araújo, \& V. R. Resende (Orgs.), Família, violência e políticas públicas: pesquisas e práticas (pp.59-87). Curitiba: CRV.

Benelli, S. J. (2012b). Políticas públicas, instituições e práticas clínicas no campo da assistência social. In G. H. Dionísio \& S. J. Benelli (Orgs.), Políticas públicas e clínica crítica (pp.63-84). São Paulo: Cultura Acadêmica.

Benelli, S. J. (2013). Um psicólogo nos conselhos municipais de assistência social e dos direitos da criança e do adolescente: construindo referências para a prática. In O. C. Mattioli, M. F. Araújo, \& V. R. Resende (Orgs.), Violência e relações de gênero: o desafio das práticas institucionais (pp.115-144). Curitiba: CRV.

Benelli, S. J., \& Costa-Rosa, A. (2010). A construção de redes sociais: entre a conexão e a captura na gestão dos riscos sociais. In E. P. Constantino (Org.), Psicologia, estado e políticas públicas (pp.25-85). Assis: Unesp. 
Benelli, S. J., \& Costa-Rosa, A. (2011). Para uma crítica da razão socioeducativa em entidades assistenciais. Estudos de Psicologia (Campinas), 28(4), 539-563. http://dx.doi.org/10.1590/S0103-166×20110 00400014

Benelli, S. J., \& Costa-Rosa, A. (2012a). Paradigmas diversos no campo da assistência social e seus estabelecimentos assistenciais típicos. Psicologia USP, 23(4), 609-660.

Benelli, S. J., \& Costa-Rosa, A. (2012b). Conselhos municipais: prática e impasses no cenário contemporâneo. Psicologia em Estudo (Maringá), 17(4), 577-586.

Benelli, S. J., \& Costa-Rosa, A. (2013). Dispositivos institucionais filantrópicos e socioeducativos de atenção à infância na Assistência Social. Estudos de Psicologia (Campinas), 30(4), 283-301. http://dx.doi.org/10.15 90/S0103-166X2013000200015

Bock, A. M. B. (Org.) (2009). Psicologia e compromisso social. São Paulo: Cortez.

Brasil. Conselho Nacional de Assistência Social. (2012a). Resolução n 33, de 12 de dezembro de 2012. Aprova a Norma Operacional Básica do Sistema Único de Assistência Social - NOB/SUAS. Brasília: CNAS.

Brasil. Conselho Nacional dos Direitos da Criança e do Adolescente. (2010b). Princípios da política nacional dos direitos humanos de crianças e adolescentes no Brasil. Brasília: Conanda.

Brasil. Ministério do Desenvolvimento Social e Combate à Fome. (2004). Política nacional de assistência social. Brasília: MDS.

Brasil. Ministério do Desenvolvimento Social e Combate à Fome. (2005). Norma operacional básica do sistema único de assistência social. Brasília: MDS.

Brasil. Ministério do Desenvolvimento Social e Combate à Fome. (2006a). Diretrizes para a estruturação, reformulação e funcionamento dos conselhos de assistência social. Brasília: CNAS

Brasil. Ministério do Desenvolvimento Social e Combate à Fome. (2006b). Orientações técnicas para o Centro de Referência da Assistência Social - CRAS. Brasília: MDS.

Brasil. Ministério do Desenvolvimento Social e Combate à Fome. (2006c). Orientações técnicas para o Programa Bolsa Família - PBF. Brasília: MDS.

Brasil. Ministério do Desenvolvimento Social e Combate à Fome. (2006d). Orientações técnicas: Centro de Referência Especializado de Assistência Social - CREAS. Brasília: MDS.

Brasil. Ministério do Desenvolvimento Social e Combate à Fome. (2009a). Orientações técnicas para o Centro de Referência da Assistência Social - CRAS. Brasília: MDS.

Brasil. Ministério do Desenvolvimento Social e Combate à Fome. (2009b). Tipificação nacional de serviços socioassistenciais. Brasília: MDS.
Brasil. Presidência da República. (1927). Decreto $n^{\circ}$ 17.943 A, de 12 de outubro de 1927. Consolida as leis de assistência e proteção a menores. Recuperado em fevereiro, 15, 2010, de http://www.ciespi.org.br/ base_legis/baselegis_view.php?id=76

Brasil. Presidência da República. (1979). Lei Federal $n^{\circ}$ 6.697, de 10 de outubro de 1979. Institui o código de menores. Brasília: MDS.

Brasil. Presidência da República. (1988). Constituição da República Federativa do Brasil. Brasília: MDS.

Brasil. Presidência da República. (1990). Lei n 8.069, de 13 de julho de 1990. Dispõe sobre o estatuto da criança e do adolescente e dá outras providências. Brasília: MDS.

Brasil. Presidência da República. (1993). Lei nº 8.742, de 7 de dezembro de 1993. Dispõe sobre a organização da assistência social e dá outras providências. Brasília: MDS.

Brasil. Presidência da República. (2010a). Construindo a política nacional dos direitos humanos de crianças e adolescentes e o plano decenal dos direitos humanos de crianças e adolescentes, 2011-2020. Brasília: Conanda.

Brasil. Presidência da República. (2010c). Orientações técnicas sobre o serviço de convivência e fortalecimento de vínculos para crianças e adolescentes de 6 a 15 anos. Brasília: MDS.

Brasil. Presidência da República. (2011). Lei n 12.435, de 6 de julho de 2011. Altera a Lei $n^{\circ} 8.742$, de 7 de dezembro de 1993, que dispõe sobre a organização da Assistência Social. Brasília: MDS.

Brasil. Presidência da República. (2012b). Lei nº 12.594/12, de 19 de janeiro de 2012. Institui o Sistema Nacional de Atendimento Socioeducativo (Sinase), e regulamenta a execução das medidas socioeducativas destinadas a adolescente que pratique ato infracional. Brasília: Conanda.

Castel, R. (1987). A gestão dos riscos: da antipsiquiatria à pós-psicanálise. Rio de Janeiro: Francisco Alves.

Coimbra, C., \& Nascimento, M. L. (2005). Ser jovem, ser pobre é ser perigoso? Estudios sobre Juventud, 9(22), 338-355.

Conselho Federal de Psicologia. (2007). Referência técnica para atuação do(a) psicólogo(a) no CRASISUAS. Brasília: Autor.

Conselho Federal de Psicologia. (2010a). Política de assistência social. Diálogos, 7(7), 3-56.

Conselho Federal de Psicologia. (2010b). Democracia e subjetividade: a produção social dos sujeitos democráticos. Brasília: Autor.

Conselho Federal de Psicologia. (2011a). V Seminário Nacional Psicologia e Políticas Públicas: subjetividade, cidadania e políticas públicas. Brasília: Autor. 
Conselho Federal de Psicologia. (2011b). VI Seminário Nacional de Psicologia e Políticas Públicas: democracia e promoção de direitos. Salvador: Autor.

Conselho Federal de Psicologia. (2013). Caderno de deliberações do VIII CNP: psicologia, ética e cidadania: práticas profissionais a serviço da garantia de direitos. Brasília: Autor.

Constantino, E. P. (Org.). (2010). Psicologia, estado e políticas públicas. Assis: Unesp.

Costa, R. (2004). Sociedade de controle. São Paulo Perspectiva, 18(1), 161-167.

Costa-Rosa, A. (2000). O modo psicossocial: um paradigma das práticas substitutivas ao modo asilar. In P. D. C. Amarante (Org.), Ensaios de loucura \& civilização (pp.141-168). Rio de Janeiro: Fiocruz.

Cruz, J. M. O. (2009). Práticas psicológicas em Centros de Referência da Assistência Social (CRAS). Psicologia em Foco, 2(1), 11-27.

Cruz, L. R., \& Guareschi, N. (2004). Sobre a psicologia no contexto da infância: da psicopatologização à inserção política. Revista Aletheia, 20(2), 77-90.

Cruz, L. R., \& Guareschi, N. (Orgs.). (2009). Políticas públicas e assistência social: diálogo com as práticas psicológicas. Rio de Janeiro: Vozes.

Cruz, L. R., \& Guareschi, N. (Orgs.). (2012). O psicólogo e as políticas públicas de assistência social. Rio de Janeiro: Vozes.

Deleuze, G. (1992). Conversações. Rio de Janeiro: Editora 34.

Demo, P. (1995). Cidadania tutelada e cidadania assistida. Campinas: Autores Associados.

Donzelot, J. (2001). A polícia das famílias. Rio de Janeiro: Graal.

Figueiredo, L. C. M. (2007). Psicologia: uma nova introdução: uma visão histórica da psicologia como ciência. São Paulo: Educ.

Foucault, M. (1979). Microfísica do poder. Rio de Janeiro: Graal.

Foucault, M. (1999). Vigiar e punir: nascimento da prisão. Petrópolis: Vozes.

Foucault, M. (2008). Segurança, território, população. São Paulo: Martins Fontes.

Goffman, E. (1987). Manicômios, prisões e conventos. São Paulo: Perspectiva.

Hardt, M., \& Negri, A. (2001). Império. São Paulo: Record.

Hillesheim, B., \& Cruz, L. R. (2009). Risco, vulnerabilidade e infância: algumas aproximações. In L. R. Cruz \& N. M. F. Guareschi (Orgs.), Politicas públicas e assistência social: diálogo com as práticas psicológicas (pp.70-85). Rio de Janeiro: Vozes.

Lima, M. J., \& Cerveny, C. M. O. (2012). A competência social do psicólogo: estudo com profissionais que atuam em instituições. Psicologia: Ciência e Profissão, 32(2), 284-303.

Lourau, R. (1995). A análise institucional. Petrópolis: Vozes.

Macedo, J. P., \& Dimenstein, M. (2009). Psicologia e a produção do cuidado no campo do bem-estar social. Psicologia e Sociedade, 21(3), 293-300.

Mendola, S. (2005). O sentido do risco. Tempo Social, 17(2), 59-91.

Moraes, T. D., \& Nascimento, M. L. (2002). Da norma ao risco: transformações na produção de subjetividades contemporâneas. Psicologia em Estudo, 7(1), 91-102.

Oliveira, C. M. C., \& Heckert, A. L. C. (2013). Os centros de referência de assistência social e as artes de governar. Fractal: Revista de Psicologia, 25(1), 145-160.

Oliveira, I. F., \& Amorim, K. M. O. (2012). Psicologia e política social: o trato da pobreza como "sujeito psicológico". Psicologia Argumento, 30(70), 559-566.

Oliveira, I. F., Dantas, C. M. B., Solon, A. F. A. C., \& Amorim, K. M. O. (2011). A prática psicológica na proteção social básica do SUAS. Psicologia \& Sociedade, 23(N. Esp.), 140-149.

Paiva, I. L., \& Yamamoto, O. H. (2010). Formação e prática comunitária do psicólogo no âmbito do "terceiro setor". Estudos de Psicologia (Natal), 15(2), 153-160.

Patto, M. H. S. (1997). Para uma crítica da razão psicométrica. Psicologia USP, 8(1), 47-62.

Patto, M. H. S. (2010). Exercícios de indignação: escritos de educação e psicologia. São Paulo: Casa do Psicólogo.

Pogrebinschi, T. (2004). Foucault, para além do poder disciplinar e do biopoder. Lua Nova, 63(1), 180-201.

Rodrigues, M. M. A. (2010). Políticas públicas. São Paulo: Publifolha.

Saliba, M. G. (2006). O olho do poder: análise crítica da proposta educativa do estatuto da criança e do adolescente. São Paulo: Unesp.

Senra, C. M. G., \& Guzzo, R. S. L. (2012). Assistência social e psicologia: sobre as tensões e conflitos do psicólogo no cotidiano do serviço público. Psicologia \& Sociedade, 24(2), 293-299.

Silva, R. C. (2002). Metodologias participativas para trabalhos de promoção de saúde e cidadania. São Paulo: vetor.

Silveira, A. F., Cobalchini, C. C. B., Menz, D. M., Valle, G. A., \& Barbarini, N. (2007). Caderno de psicologia e políticas públicas. Curitiba: CRP Paraná. (Coletânea Psi-Série Técnica).

Siqueira, A. C., \& Dell'Aglio, D. D. (2011). Políticas públicas de garantia do direito à convivência familiar e comunitária. Psicologia \& Sociedade, 23(2), 262-271. 
Souza, M. A. (2012). Caridade e educação: assistencialismo e moralização dos pobres, 1930-1990. São Paulo: Annablume.

Traversini, C. S., \& Bello, S. E. L. (2009). O numerável, o mensurável e o auditável: estatística como tecnologia para governar. Educação e Realidade, 34(2), 135-152.

Vasconcelos, E. M. (2008). Abordagens psicossociais: história, teoria e trabalho no campo. São Paulo: Hucitec.

Vaz, P. (1999). Corpo e risco. Fórum Media, 1(1), 101-111. Recuperado em setembro 5, 2012, de www.eco.ufrj. br/ciberidea/artigos/corpo/pdf/corpoerisco.pdf

Yamamoto, O. H. (2007). Políticas sociais, "terceiro setor" e "compromisso social": perspectivas e limites do trabalho do psicólogo. Psicologia e Sociedade, 19(1), 30-37.

Yamamoto, O. H., \& Oliveira, I. F. (2010). Política social e psicologia: uma trajetória de 25 anos. Psicologia: Teoria e Pesquisa, 26(N. Esp.), 9-24.

Zaniani, E. J. M. (2008). Sob os auspícios da proteção: Moncorvo Filho e a higienização da infância (Dissertação de mestrado não-publicada). Universidade Estadual de Maringá, Paraná.

Recebido: novembro 22, 2013

Versão final: maio 4, 2015

Aprovado: julho 1, 2015 
